\title{
EFFECT OF FLOW STRUCTURE ON HEAT TRANSFER IN COMPACT HEAT EXCHANGER BY USING FINITE THICKNESS WINGLET AT ACUTE ANGLE
}

\author{
Bhupender Sharma ${ }^{1},{ }^{*}$, Gian Bhushan ${ }^{2}$, Gulshan Sachdeva ${ }^{2}$ \\ Keywords: Longitudinal vortices, vortex generator, finite thickness, triangular channel, Heat Transfer \\ enhancement
}

\begin{abstract}
Longitudinal vortex generation is a well-known passive technique for thinning the thermal boundary layer and hence enhancing the heat transfer, but its performance while considering the thickness is essentially unknown. In this study, a single triangular shaped winglet type vortex generator having finite thickness is analyzed in a plate fin heat exchanger with triangular inserts as secondary fins. The vortex generators are mounted on bottom and top plates of the heat exchanger and triangular inserts forms a channel, each representing the symmetry for the gasside element of the compact heat exchanger. Heat transfer and pressure drop is computed to determine the effectiveness of the vortex generator while varying its thickness, size, and angle of attack under confined laminar flow condition. In addition the winglet is tilted from vertical at an angle known as acute angle and it was found to produce two longitudinal vortices which better did the thinning of boundary layer. It is shown that adding thickness to triangular winglet and mounting at $\psi=45^{\circ}$, augment heat transfer along the channel wall as high as $19.7 \%$ with a corresponding increase of $7.8 \%$ in pressure loss.
\end{abstract}

\section{INTRODUCTION}

Improvement in the performance of heat exchangers with gases as working fluid becomes particularly necessary, because of the high thermal resistance of the gases. To compensate for the poor heat transfer properties of the gases, surface area density of the heat exchanger may be increased and the use of ribs, baffles, wings or winglets is the most preferred option to increase the surface area volume ratio. These obstacles produces vortices which disturb the flow structure and causes heat transfer enhancement either locally or globally depending upon the nature of the vortices. Two types of vortices can be produced i.e. longitudinal and transverse. Longitudinal vortices are proved to be better for heat transfer enhancement than transverse vortices as shown by M.Fiebig [1]. A variety of experimental and a considerable amount of analytical and computational research have been carried out on vortex generators for the enhancement of heat transfer. Mostly these studies are related to the rectangular channel and of fin-tube heat exchangers. A.M. Jacobi \&R. K. Shah [2] has given a state of art review on longitudinal vortices (LV's) and found that the flat plate having vortex generators was of great interest for many researchers. Torii et al. [3] evaluated the local heat transfer enhancement with a single delta winglet mounted on a flat plate. A. Y. Turk and G. H. Junkhan[4] predicted the heat transfer increment by using multiple rectangular winglet vortex generators at the leading edge of a flat plate. The first systematic experimental study of the use of vortex generator (wing and winglet) for heat transfer enhancement was reported by Fiebig et al. [5,6]. They used liquid crystal thermography to measure the heat transfer enhancement. They found increase in local heat transfer coefficient and the mean heat transfer was enhanced by more than $50 \%$.

Biswas et. al. [7] numerically studied the developing laminar mixed convection in a rectangular channel with wing-type vortex generators at Reynolds numbers of 500 and 1815 . The channel plates were not stamped to make the delta wings; rather these were joined to the plates. G. Biswas and H. Chattopadhyay [8] further extended this numerical model by considering the stamped delta wing for forced convection heat transfer. It was concluded that the performance of the stamped delta wing was slightly inferior. As the production of stamped vortex generators is easier, their study is more valuable to the manufacturers. Biswas et al. [9] further investigated the flow structure and heat transfer in a channel with a built-in-winglet type vortex generator in a fully developed laminar flow. The computed results were validated with the experiments conducted using hot-wire-anemometer. Vasudevan et al. [10] numerically studied the potential of delta winglets mounted on the slant surfaces of the triangular secondary fins of the plate fin heat exchanger. Liou et al. [11] experimentally predicted detailed local

This paper was recommended for publication in revised form by Ahmet Selim Dalkılıç

${ }^{1}$ Research Scholar, National Institute of Technology, Kurukshetra, Haryana, India

${ }^{2}$ Graduate Faculty, National Institute of Technology, Kurukshatra, Haryana, India

*E-mail address: nitkkr.bsharma@gmail.com 
Nusselt number distributions in the first pass of a sharp turning two-pass square channel with twelve different configurations of longitudinal vortex generator. The delta wing was found to have $170 \%$ enhancement in the heat transfer with $30 \%$ increase in the friction factor.

A.Sohankar, and L.Davidson [12] studied 3-dimensional unsteady flow and heat transfer in a channel with inclined block shaped vortex generators mounted on one side of a channel flow for two Reynolds numbers, i.e. $\mathrm{Re}=400$ and 1500. A. Sohankar [13] studied the unsteady flow and heat transfer using LES and DNS for a channel with two angled ribs as a ' $V$ ' shaped vortex generator to enhance the heat transfer. Hiravennavar et al. [14] investigated the flow structure and heat-transfer enhancement by a winglet pair of finite thickness mounted on a flat plate. It was found that the winglet of finite thickness was superior to the zero thickness winglet. J.M. Wu, and W.Q.Tao, $[15,16]$ presented numerical results on laminar convection heat transfer in a channel with a rectangular winglet pair punched out from the lower wall of the channel. The effect of the punched area and the thickness of the rectangular winglet pair to the heat transfer were numerically studied. Tian et al. [17] performed three dimensional simulations on laminar heat transfer and fluid flow characteristics of a channel with rectangular winglet pair (RWP) and delta winglet pair (DWP). Sachdeva et al. [18,19] attempted heat transfer characteristics with secondary flow analysis in plate triangular fin heat exchanger with delta and rectangular wing vortex generator.This geometrical configuration was investigated for various angles of attack of the wing i.e. $15^{\circ}, 20^{\circ}, 26^{\circ}$ and $37^{\circ}$ but Reynolds numbers not exceeding 200.

Gupta et al. [20] reported the potential of a winglet pair type vortex generator for the heat transfer enhancement in a plate fin heat exchanger, with triangular fins as inserts. The computations was performed at $R e=200$ and placing the winglet at an angle of attack, $\beta=20^{\circ}$. The predicted results showed that the heat transfer is increased by 13 per cent, even at the exit, with the winglet pair.Jang et. al. [21] studied numerically the thermalhydraulic characteristics of block type vortex generators (VG) mounted behind the tubes. Simplified conjugategradient method (SCGM) was used. The results showed that at $\mathrm{ReDh}=400-1200$ the maximum area reduction ratios reached $14.9-25.5 \%$. When staggered arrangement used the maximum area reduction ratio was achieved by 7.9-13.6\%.

Leandro et. al. [22] investigated influence of VG roll angle on heat transfer enhancement by optimization of VG position and angles in a fin-tube compact heat exchanger using the Genetic Algorithm. Two approaches were evaluated considering Response Surface Methodology applying Neural Networking method, and Direct Optimization. It was concluded that the optimized VG configurations led to heat transfer enhancement rates higher than previous work reported in literature. $\mathrm{Li}$ et al.[23]performed numerical investigation on the pair of punched/mounted rectangular and delta winglet type vortex generators to enhance the heat transfer of the air-side of the fin tube heat exchanger. The predicted results showed that using LVGs in plain fin channel increases Nusselt numbers up to $20 \%$ w.r.t. plain fins channel without LVGs. From the above review it can be concluded that various experimental and numerical investigation had been carried out to establish the use of longitudinal vortex generator in heat transfer enhancement. However, very little research has been done to evaluate the performance of the finite thickness vortex generators mounted in the triangular channel, in a compact heat exchanger. The prediction of the details of the flow structure and the influence of thickness of winglet on heat transfer by numerical solution in the triangular fins of a plate-fin heat exchanger is the essential goal of this study.

\section{PROBLEM FORMULATION}

Figure 1(a) shows the plate fin heat exchanger with triangular inserts placed between the plates. It is a cross flow heat exchanger. The computation domain is a triangular shaped passage formed by the surface of secondary fin with the plate of plate-fin heat exchanger as shown in Figure 1(b). The triangular winglet shaped vortex generator is fixed with its base i.e., a single winglet is attached on the surfaces $\mathrm{ABA}^{\prime} \mathrm{B}^{\prime}$ and $\mathrm{AEA}^{\prime} \mathrm{E}^{\prime}$ of the plate. The plane of the triangular winglet makes an angle of attack $(\beta)$ with the direction of flow.

In the numerical scheme the computational domain is divided in Cartesian mesh. Staggered grid arrangement is used in which velocity components are defined at the center of cell faces to which they are normal and the pressure and temperature are defined at the center of the cell as shown in figure 2. Air is considered as the working fluid. In a plate-fin heat exchanger the fin spacing on the gas side is small and the mean velocity is low. So, the laminar flow is considered. 


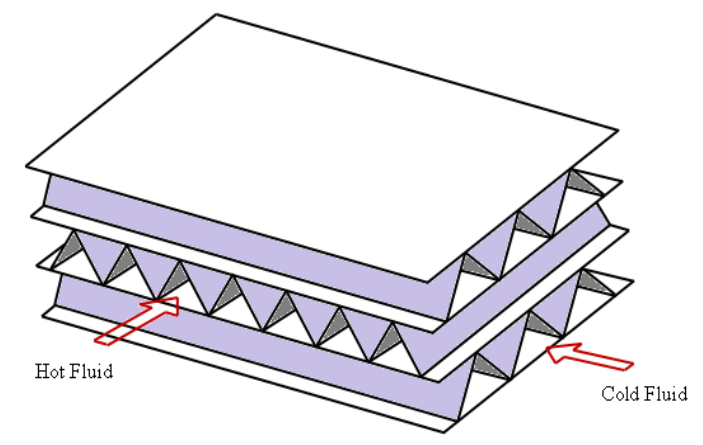

(a)

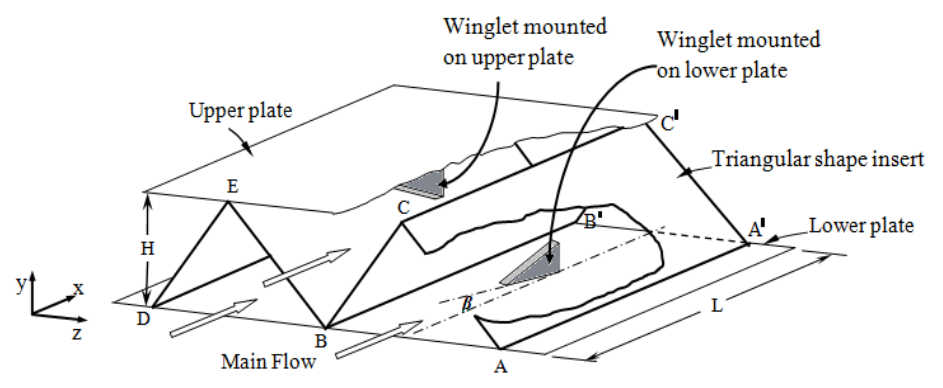

(b)

Figure 1. (a) Model of Compact Heat Exchanger (b) Triangular inserts and winglet mounted

Figure 3(a) shows the orientation of the vortex generator (winglet) when it is perpendicular to the plate of heat exchanger and figure 3(b) depicts the geometry of the triangular winglet vortex generator when it is inclined at an angle $\psi$ to the plate of heat exchanger.

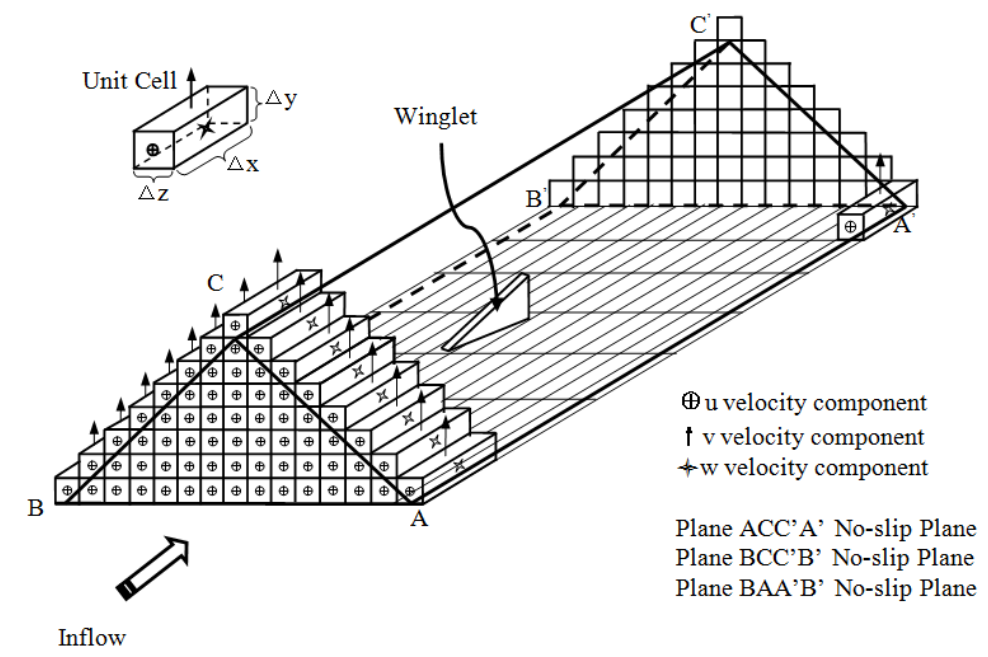

Figure 2. Computational domain with staggered grid mesh showing the location of velocity components

The computational grid with staggered grid arrangement of velocity and pressure is shown in figure 2 . Finite-difference method is used to convert governing equations into the algebraic form. The convection terms in the equations are discretized using second order upwind scheme, and the diffusion terms are discretized by central difference scheme. The coupling between pressure and velocity is implemented by the modified version of MAC method due to Harlow and Welch [21] and Hirt and Cook [22]. A staggered grid system of $81 \times 20 \times 41$ grid points is adopted typically in the computation domain. A careful check for the grid-independence of the numerical 
solutions has been made to ensure the accuracy and validity of the numerical results. For this purpose, three grid systems, $88 \times 20 \times 41,92 \times 20 \times 41$ and $161 \times 40 \times 81$, are tested.

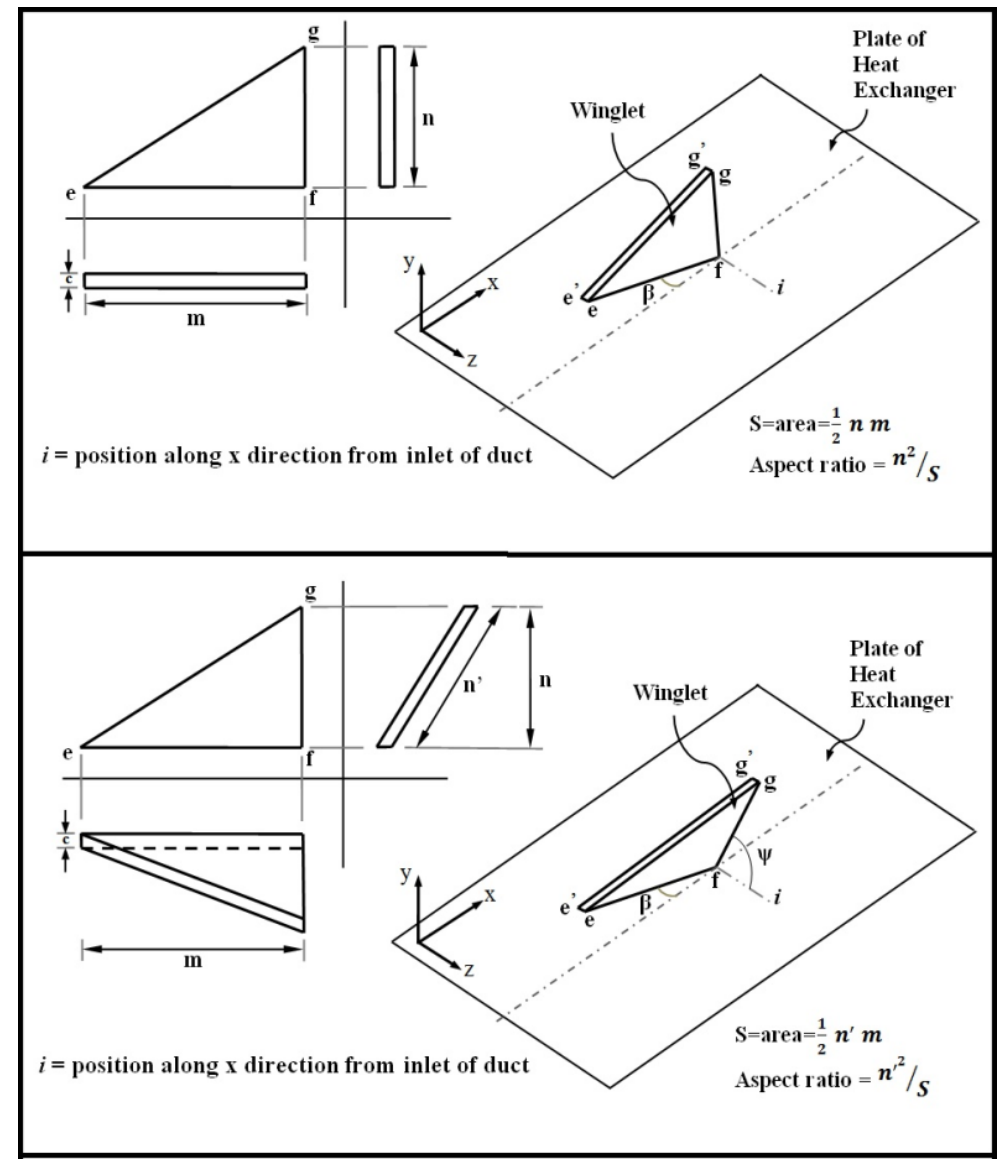

Figure 3.(a) Finite thickness triangular winglet, (b) Finite thickness triangular winglet at acute angle $\psi$

\section{Governing Equations}

\section{Continuity Equation}

$\frac{\partial U}{\partial X}+\frac{\partial V}{\partial Y}+\frac{\partial W}{\partial Z}=0$

Momentum Equations

$\frac{\partial U}{\partial \tau}+\frac{\partial U^{2}}{\partial X}+\frac{\partial U V}{\partial Y}+\frac{\partial U W}{\partial W}=-\frac{\partial P}{\partial X}+\frac{1}{R e}\left[\frac{\partial^{2} U}{\partial X^{2}}+\frac{\partial^{2} U}{\partial Y^{2}}+\frac{\partial^{2} U}{\partial Z^{2}}\right]$

$\frac{\partial V}{\partial \tau}+\frac{\partial U V}{\partial X}+\frac{\partial V^{2}}{\partial Y}+\frac{\partial V W}{\partial W}=-\frac{\partial P}{\partial Y}+\frac{1}{\operatorname{Re}}\left[\frac{\partial^{2} V}{\partial X^{2}}+\frac{\partial^{2} V}{\partial Y^{2}}+\frac{\partial^{2} V}{\partial Z^{2}}\right]$

$\frac{\partial W}{\partial \tau}+\frac{\partial U W}{\partial X}+\frac{\partial V W}{\partial Y}+\frac{\partial W^{2}}{\partial W}=-\frac{\partial P}{\partial Z}+\frac{1}{\operatorname{Re}}\left[\frac{\partial^{2} W}{\partial X^{2}}+\frac{\partial^{2} W}{\partial Y^{2}}+\frac{\partial^{2} W}{\partial Z^{2}}\right]$

Energy Equation 
$\frac{\partial \theta}{\partial \tau}+\frac{\partial U \theta}{\partial X}+\frac{\partial V \theta}{\partial Y}+\frac{\partial W \theta}{\partial W}=\frac{1}{\operatorname{Re} \cdot \operatorname{Pr}}\left[\frac{\partial^{2} \theta}{\partial X^{2}}+\frac{\partial^{2} \theta}{\partial Y^{2}}+\frac{\partial^{2} \theta}{\partial Z^{2}}\right]$

\section{Evaluation of the Performance Parameters}

In order to have a quantitative evaluation of the heat transfer performance, the bulk temperature, combined spanwise average Nusselt number, friction factor, and Stanton number were taken

$$
\begin{aligned}
& \theta_{b}(x)=\frac{\left(\int_{A_{c}}|U| \theta d A_{c}\right)}{\left(\int_{A_{c}}|U| d A_{c}\right)} \\
& N u_{s a}=\frac{H}{k P} \frac{\left(\int_{P} d P\right)}{\left(T_{b}(x)\right)-\left(T_{w}(x)\right)} \\
& f=\frac{(\Delta P)}{\left(0.5 \times \rho U_{a v}^{2}\right)}\left(\frac{H}{k P}\right) \\
& . S t=\frac{N u}{R e . P r}
\end{aligned}
$$

\section{BOUNDARY CONDITIONS \\ Velocity Boundary Conditions for Domain}

The concerned computational domain is $A B C A{ }^{\prime} B^{\prime} C^{\prime}$ ' as shown in figure 2. It has three no slip walls viz., ABB'A' and BCC'B' and ACC'A'. At the channel inlet uniform flow conditions are assumed. $U=1$ and $V=W=0$ and at the exit a smooth transition through the out flow boundary is ensured by the setting the condition due to Orlanski [23] $\mathrm{Uc}=1$ in the present case.

Inclined no-slip planes pass through the nodal points of $\mathrm{V}$ and $\mathrm{W}$ velocity components as shown in Figure 4. For the cells adjacent to the inclined no-slip plane Vi,j,k, Wi,j,k-1, Wi,j+1,k velocity components are set zero directly and by setting $U i, j, k-1=-U i, j, k$ and $U i, j+1, k=-U i, j, k$, the condition $U=0$ satisfies on the upper inclined no-slip plane.

$U_{i, j, k+1}=\frac{U_{i, j, k}+U_{i, j-1, k+1}}{2}$

$U_{i, j+1, k}=\frac{U_{i, j, k}+U_{i, j+1, k-1}}{2}$

The cell faces for the V-velocity nodal points lie on this boundary and are assigned zero value directly. Thus the velocity components $\mathrm{Vi}, \mathrm{j}-1, \mathrm{k}, \mathrm{Vi}, \mathrm{j}-1, \mathrm{k}+1$ are set equal to zero and the $\mathrm{U}$ and $\mathrm{W}$ velocity components of the cells below the horizontal plane are set equal and opposite to the respective velocity components just above the horizontal no-slip plane.

Implementing this condition for the cells above the horizontal plane satisfies the no-slip boundary conditions on the horizontal plane. 


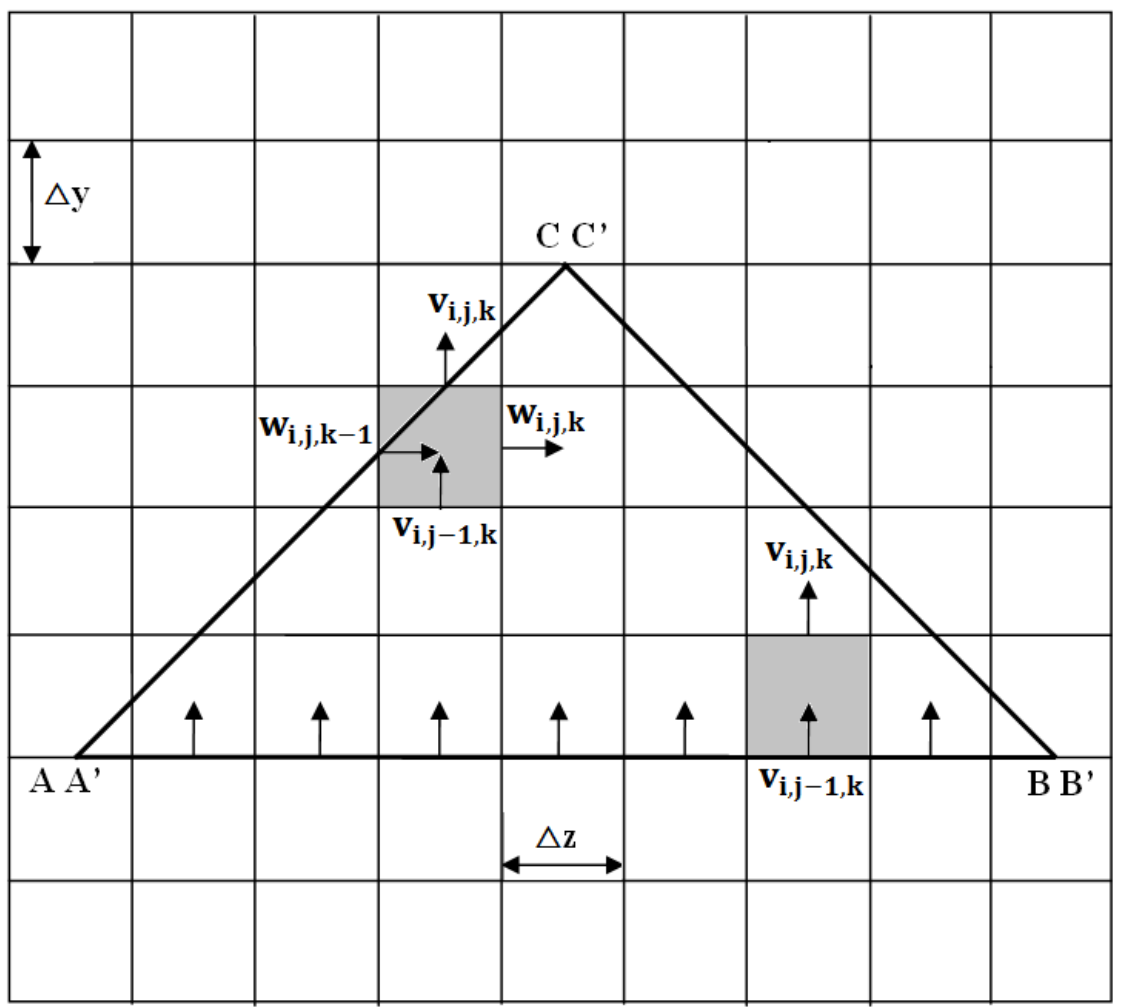

Figure 4. V and W velocity boundary condition on inclined AA ' $\mathrm{C}^{\prime} \mathrm{C}, \mathrm{BB}{ }^{\prime} \mathrm{C}^{\prime} \mathrm{C}$ and $\mathrm{AA} \mathrm{A}^{\prime} \mathrm{B}$ 'B no slip wall for Navier-Stokes equation

$U_{i, j-1, k}=-U_{i, j, k} \quad$ and $\quad W_{i, j-1, k}=-W_{i, j, k}$

\section{Velocity Boundary Conditions for Winglet}

While considering the winglet in the vertical plane, it lies mid-way between pairs of adjacent V-velocity locations as shown in figure 5 (a). Hence at the time of advancing these $\mathrm{V}$-velocity component lying on one side of the winglet surface is set equal in magnitude and opposite in direction to its value on the other side. This is done so that the value of $\mathrm{V}$ component of velocity on the winglet surface becomes equal to zero. In other words, by this procedure the no-slip boundary condition for the surface of the triangular winglet gets implemented. With the addition of thickness similar boundary condition are implemented by advancing $\mathrm{k}$ to $\mathrm{k}+1$.

$V_{i, j, k+1}=-V_{i, j, k} \quad$ and $\quad V_{i-1, j, k+1}=-V_{i, j, k}$

When triangular winglet is inclined at an angle $\psi$, plane of winglet lies mid-way of $\mathrm{U}, \mathrm{V}$ and $\mathrm{W}$ velocity components as shown in figure 5 (b). Then no-slip condition for the $\mathrm{U}, \mathrm{V}$ and $\mathrm{W}$ velocity components on the winglet plane is managed by interpolating the values and setting them equal to zero. Hence the $\mathrm{U}, \mathrm{V}$ and $\mathrm{W}$ velocity components on one side of the plane are set equal and opposite to the other side of the winglet plane.

Implementing the below mentioned conditions for the cells above the winglet plane satisfies the no-slip boundary conditions on the winglet plane.

$$
\begin{aligned}
& U_{i-1, j-1, k}=-U_{i-1, j, k} \\
& V_{i, j-1, k+1}=-V_{i, j-1, k} \\
& W_{i, j-1, k}=-W_{i, j, k}
\end{aligned}
$$




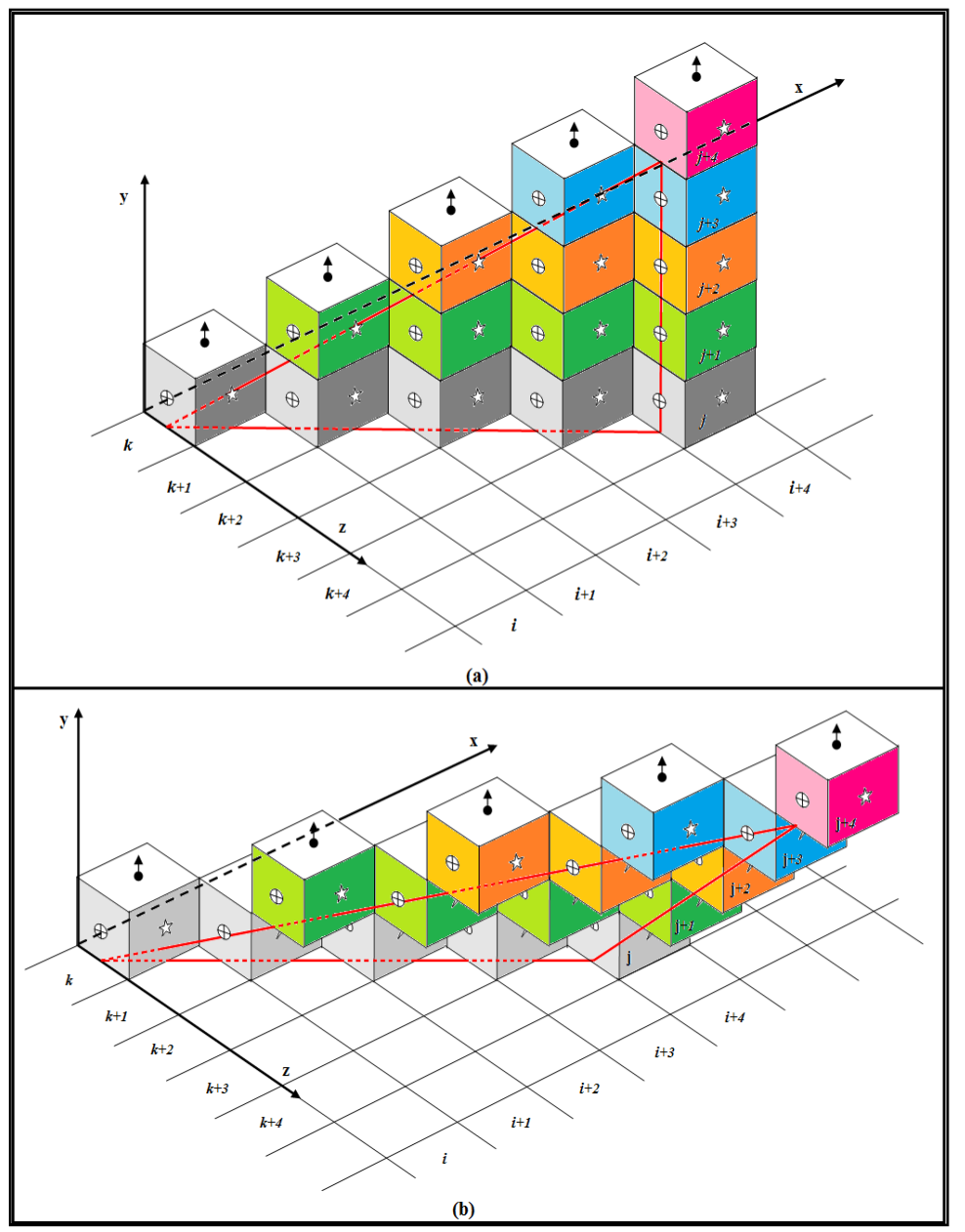

Figure 5. U, V and $\mathrm{W}$ velocity boundary condition on vertical and inclined winglet

And using the below mentioned conditions for the cells below the winglet plane satisfies the no-slip boundary conditions on the winglet plane.

$$
\begin{aligned}
& U_{i-1, j+1, k}=-U_{i-1, j, k} \\
& V_{i, j-1, k-1}=-V_{i, j-1, k} \\
& W_{i, j+1, k}=-W_{i, j, k}
\end{aligned}
$$

These conditions are extended in $\mathrm{Z}$ direction according to the thickness of the winglet. These boundary conditions are numerically applied to the governing equations at the location of the winglet vortex generator.

\section{RESULTS AND DISCUSSION}

The present study is carried out for the air with $\operatorname{Pr}=0.71$ flowing at the Reynolds number of 150 . Attack angle $\beta$ of $27^{\circ}$ is considered. Vortex generator thickness is varied along with two type of mounting arrangements; 1) with the aforesaid angle of attack triangular winglet kept perpendicular $\psi\left(90^{\circ}\right)$, to the plate of heat exchanger on which it is mounted. 2) Triangular winglet kept at an acute angle $\psi\left(45^{\circ}\right)$ to the plate on which it is mounted. To maintain constant blockage (projected area of mounted winglet) of the flow in the channel, winglets area is varied accordingly. The leading edge of the winglet lies at $\mathrm{X}_{i}=2.747$ to ensure fully developed flow.

Figure 6 illustrates the variation in $\mathrm{St}_{\mathrm{m}} / \mathrm{St}_{\mathrm{o}}$ to $\mathrm{c} / 2 \mathrm{H}$ (non dimensional thickness of vortex generator) with varying thickness of vortex generator. To evaluate the heat transfer performance in terms of Stanton Number; firstly, spanwise average Nusselt number was computed by taking the average of local Nusselt number all around the periphery of the triangular channel wall. 


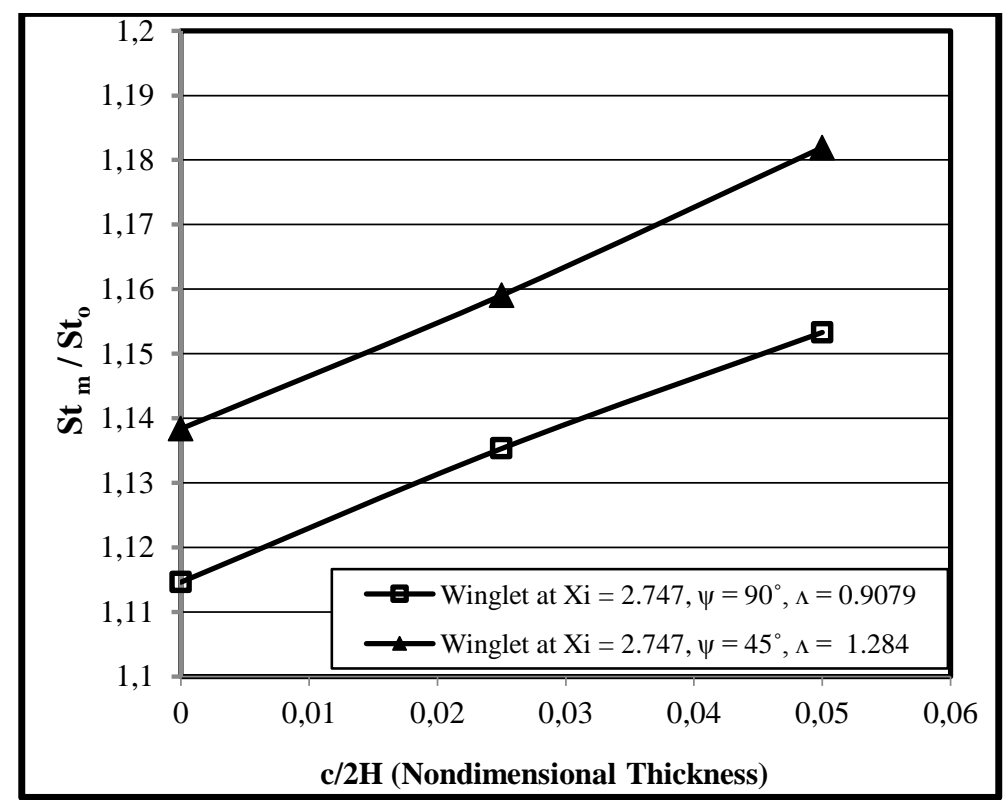

Figure 6. Variation of $\mathrm{St}_{\mathrm{m}} / \mathrm{St}_{\mathrm{o}}$ with $\mathrm{c} / 2 \mathrm{H}$ (Non-dimensional thickness of winglet) $\& \psi$

The vortex generator employed in the channel leads the main flow in to swirl flow and enhances the mixing of the hot and cold fluid. Thus, the local Nu number between the regions of vortex generators and wall is greatly improved hence increase in Stanton number is obtained. Figure 6 shows that with increasing non dimensional thickness $(\mathrm{c} / 2 \mathrm{H})$ of a vortex generator increase the $\mathrm{St}_{\mathrm{m}} / \mathrm{St}_{\mathrm{o}}$. Vortex generator of non-dimensional thickness $(\mathrm{c} / 2 \mathrm{H})$ of 0.025 inclined at $\psi=90^{\circ}$ increase the heat transfer by $1.92 \%$ as compared to zero thickness vortex generator.

Winglet tilted at an angle $\psi$ of $45^{\circ}$ to the plate of heat exchanger, figure 6 shows that the heat transfer performance is improved by $2.43 \%$ w.r.t zero thickness at $\psi\left(90^{\circ}\right)$, which is due to the horseshoe vortex occurring at the trailing edge of the vortex generator and swirls upstream. A pair of longitudinal vortices are also seen downstream of the vortex generator.

The fluid pressure drops mainly due to the skin friction and change in momentum. As for the case of fully developed flow through channel, the velocity profile is invariant across any flow cross section. Consequently, the

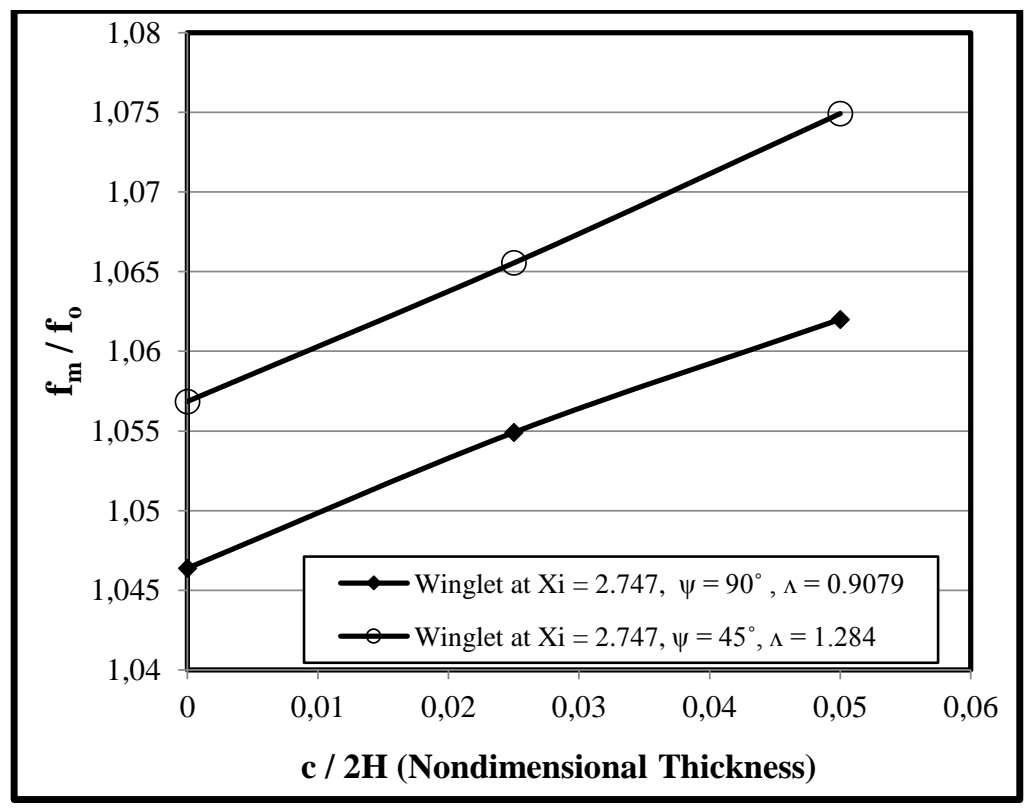

Figure 7. Variation of $\mathrm{f}_{\mathrm{m}} / \mathrm{f}_{\mathrm{o}}$ with $\mathrm{c} / 2 \mathrm{H}$ (Non-dimensional thickness of winglet) $\& \psi$ 
wall shear stress does not change axially, and the average friction factor is the same as the local friction factor for that part of the channel after the hydrodynamic entry length. Introducing vortex generator in the channel produces swirl motion upstream the flow behind the vortex generator. This cross flow (swirl motion) entails the momentum difference in the channel, which causes pressure drop.

On the other hand vortex generation acts as a blockage (projected area of vortex generator) in the main flow stream, which depends on aspect ratio $(\Lambda)$ and angle of attack $\beta$. As the thickness of vortex increases, it supplies more surface and frontal blockage, From figure 7 it shows that, there is a slight increase in friction factor.

With the second case of winglet type vortex generator when it is tilted at an angle $\psi\left(45^{\circ}\right)$ w.r.t the plate of heat exchanger, the winglet type vortex generator reduces the blockage in the channel, but to maintain the same blockage, the height of winglet is increased and thus total area of winglet increases (Figure $3 \mathrm{~b}$ ). Figure 7 clearly depicts that friction factor increases quite imprecisely. It is due to the skin friction, which depends on the vortex generator contact area (S), boundary layer thickness and to some extent on winglet thickness (c). Thus, the friction factor is increased in the channel flow. The pressure penalty in terms of friction factor computed in the present work is $1.02 \%$ with adding $\mathrm{c} / 2 \mathrm{H}$ amount of non dimensional thickness w.r.t the zero thickness at $\psi\left(90^{\circ}\right)$.

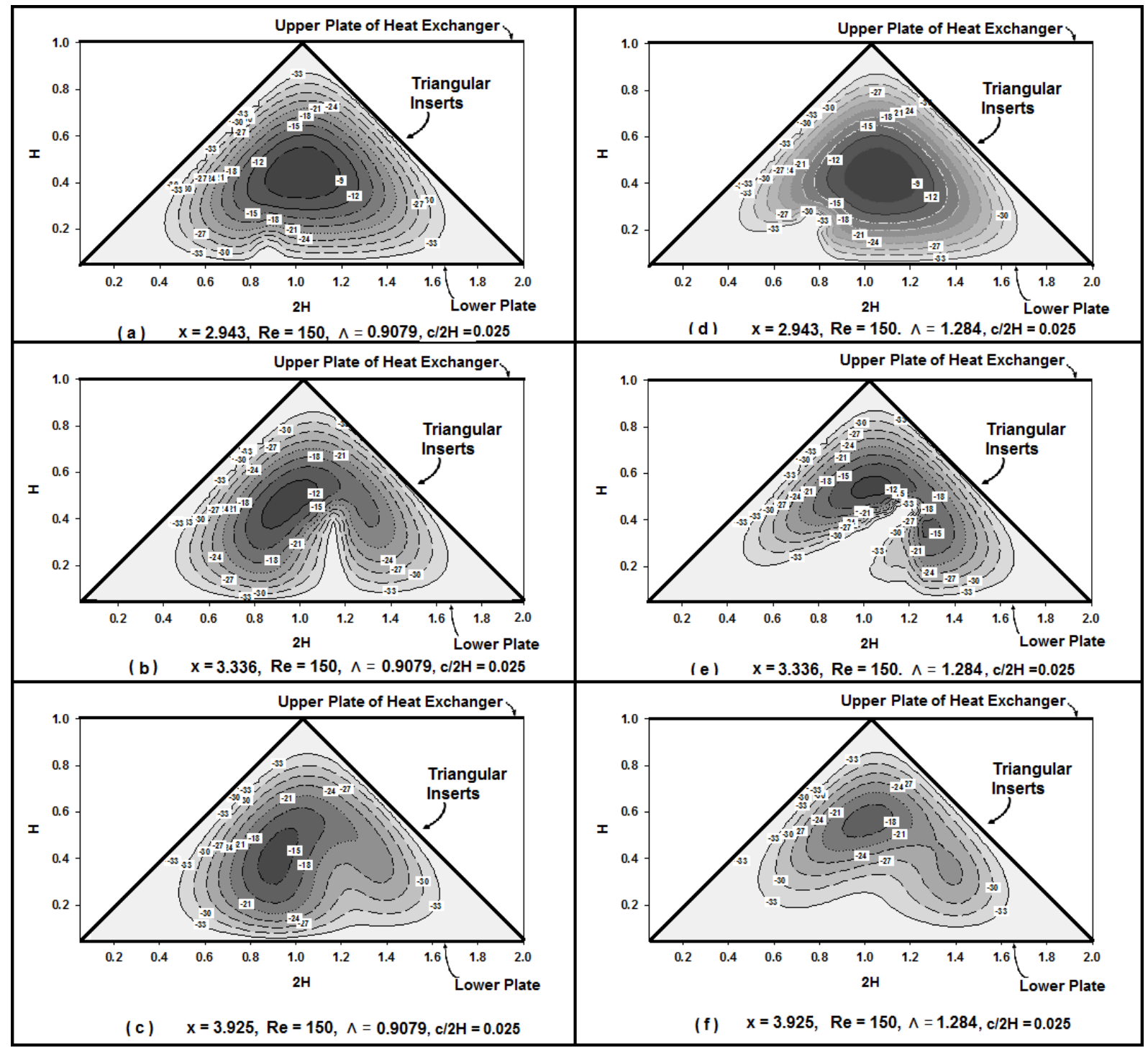

Figure 8. Contour plots showing isotherm lines at different cross section for winglet at (a) \& (b) along the winglet at $\mathrm{X}_{i}=2.948 \& \mathrm{X}_{i}=3.336$ respectively, $\mathrm{Re}=150, \Lambda=0.9079, \psi=90^{\circ}$ and (c) behind the winglet at $\mathrm{X}_{i}=3.925$. Contour plots showing isotherm lines at different cross section for winglet at (d) \& (e) along the winglet at $\mathrm{X}_{i}=2.948 \& \mathrm{X}_{i}=3.336$ respectively, $\mathrm{Re}=150, \Lambda=0.1 .284, \psi=45^{\circ}$ and (c) behind the winglet at $\mathrm{X}_{i}=3.925$. 
Figure 8 shows the thermal transport contour plot for the core central cross flow channel region from the heated, constant-temperature walls. The thermal transport is increased near the winglet regions and largest in the cross-flow just behind the winglet regions. The strong secondary flows cause large additional thermal transport into the channel. Heat transfer is enhanced in the whole computed domain compared to the flow in channel without winglet.

The heat transfer enhancement induced by the vortex generators to the channel flow increases with nondimensional thickness $(\mathrm{c} / 2 \mathrm{H})$ and acute angle $\psi\left(45^{\circ}\right)$ of winglet reaches values 3 times greater than those of the channel flow without winglet.

Tilting winglet at an acute angle $\psi$ of $45^{\circ}$ have a strong influence on the velocity field; as the flow advances through winglet it forms two vortex flow (main and small vortex) which increases velocities and the thermal transport such that the heat transfer enhancement was increased by $3.8 \%$.

Heat transfer characteristics of the channel are predicted by the bulk temperature which is directly a measure of thermal energy. Figure 9 shows the axial growth of bulk temperature. The bulk temperature of the fluid flowing in a plate-fin channel even without any vortex generator increases along the channel length due to the transfer of heat from the heated fin surfaces to the cold fluid.

While adding thickness to the winglet is marked rise to the bulk temperature which is depicted from figure 9. Further, tilting winglet at an acute angle $\psi\left(45^{\circ}\right)$ gives accountably more growth to the bulk temperature. The heat transfer enhancement effect of the triangular winglet can be quantified in terms of reduction of size of the heat exchanger that can be accomplished using the thickness and tilting of the triangular winglet. The length of the heat exchanger $(\mathrm{x} / \mathrm{H})$ required for attaining an exit bulk temperature of, say 0.77 , the reduction in length of $31.25 \%$ is achieved corresponding to the non-dimensional thickness $\mathrm{c} / 2 \mathrm{H}=0.05$ at $\psi=90^{\circ}$. While considering the acute angle of $\psi=45^{\circ}$ with $\mathrm{c} / 2 \mathrm{H}=0.05$, reduction in length is $50 \%$.

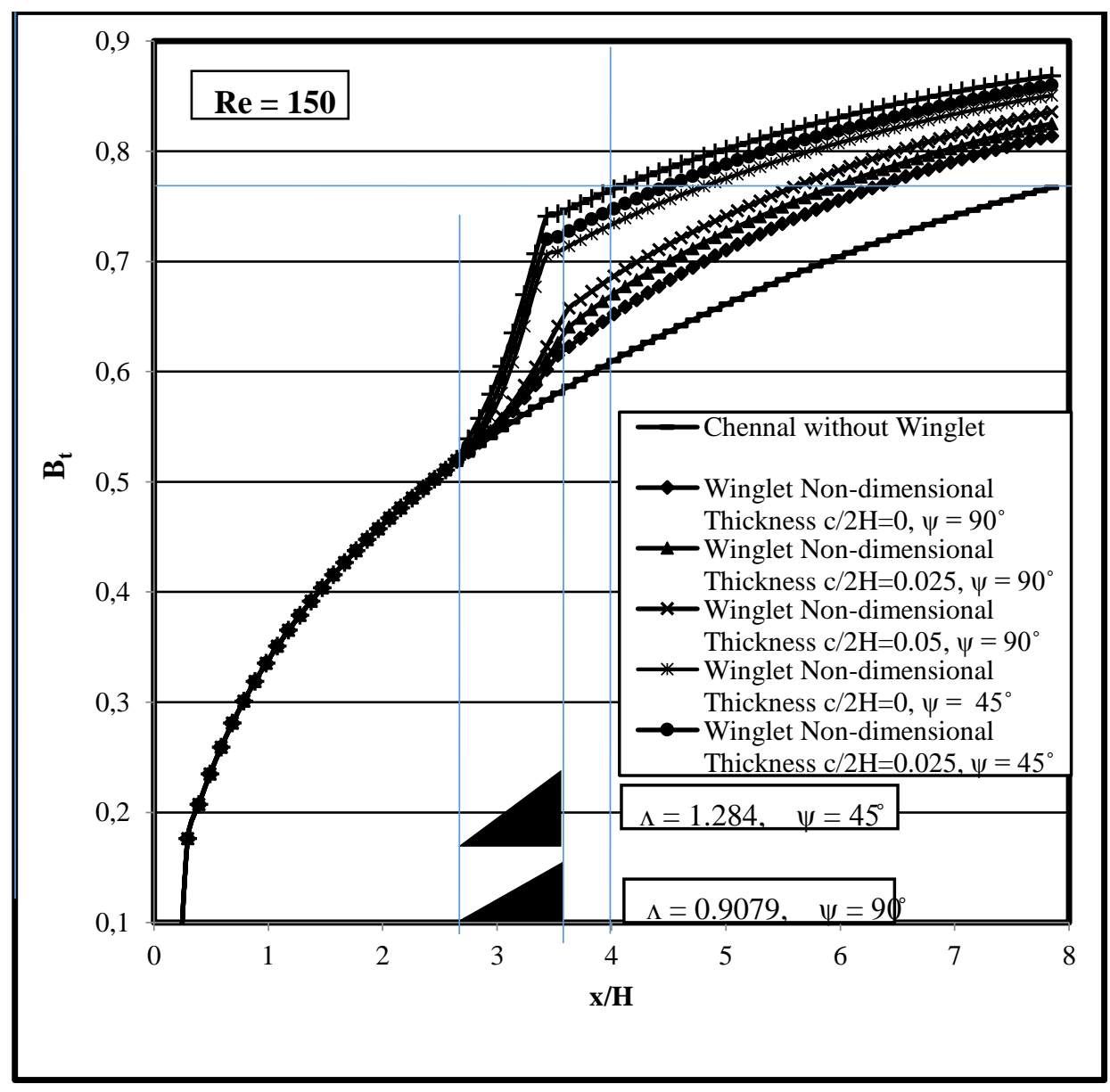

Figure 9. Bulk temperature growth along the length of heat exchanger for two mounting arrangement i.e. $\psi=90^{\circ}$ $\& 45^{\circ}$ 
Table 1.Geometrical parameters for triangular channel with and without winglet

\begin{tabular}{|l|c|c|c|c|}
\hline \multirow{2}{*}{ Geometry } & $\begin{array}{c}\text { Winglet } \\
\text { angle } \\
\end{array}$ & $\begin{array}{c}\text { Non Dimensional } \\
\text { Thickness of } \\
\text { winglet }(\mathbf{c} / \mathbf{2 H})\end{array}$ & $\begin{array}{c}\text { Heat Exchanger } \\
\text { Non Dimensional } \\
\text { Length }(\mathbf{x} / \mathbf{H})\end{array}$ & $\begin{array}{c}\text { \% } \\
\text { Reduction }\end{array}$ \\
\hline Triangular channel without winglet & - & - & 8.0 & - \\
\hline \multirow{3}{*}{ Triangular channel with winglet } & \multirow{3}{*}{$90^{\circ}$} & 0 & 6.2 & 22.5 \\
\cline { 3 - 5 } & & 0.025 & 5.8 & 27.5 \\
\cline { 3 - 5 } & \multirow{3}{*}{$45^{\circ}$} & 0.05 & 5.45 & 31.87 \\
\cline { 3 - 5 } & & 0 & 4.56 & 43.0 \\
\cline { 3 - 5 } & & 0.025 & 4.28 & 46.5 \\
\cline { 3 - 5 } & & 0.05 & 4.0 & 50.0 \\
\hline
\end{tabular}

\section{VALIDATION OF THE CODE}

The computer code is reduced to the fundamental case of a rectangular channel without any secondary inserts or vortex generators so as to compare the results with those presented by Biswas et al. [9] as shown in Figure 10. These computations are performed on Core 2 Duo PCs operating on Windows XP with staggered grids of $51 \times 20 \times 41$ points along $\mathrm{x}, \mathrm{y}$ and $\mathrm{z}$ directions. The aspect ratio of the channel is 2 and the Reynolds number is 1580 . It can be seen that the present results are in good agreement with the published values and hence, the validity of the numerical scheme and computer code is established. The maximum percentage error $18.47 \%$ and the average percentage error is $5.09 \%$.

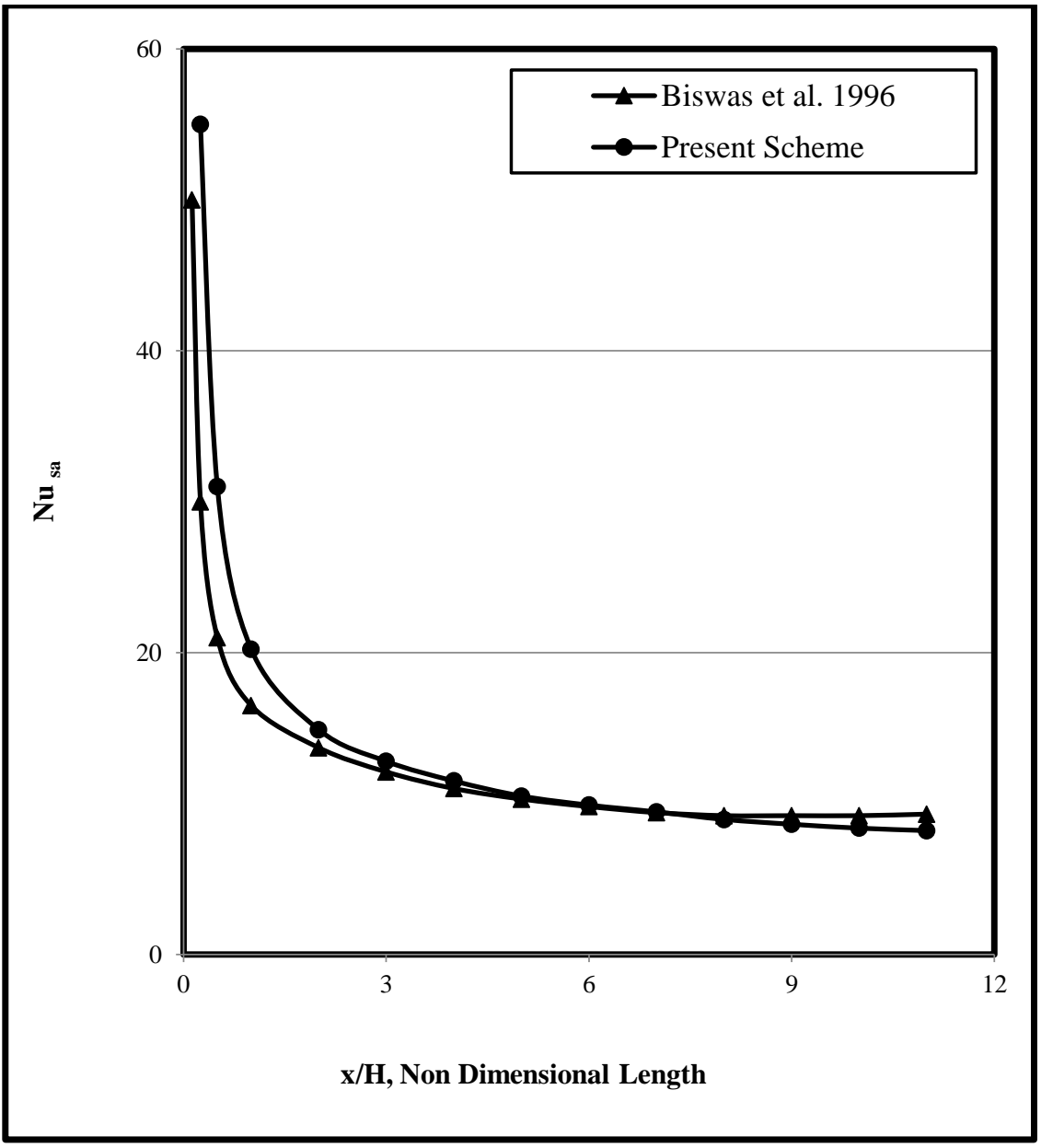

Figure 10.Validation of Code shown with Spanwise average Nusselt Number 


\section{CONCLUSION}

Fluid flow and heat transfer in plate-fin heat exchangers using winglet type vortex generator with finite thickness $(\mathrm{c} / 2 \mathrm{H}) 0.00,0.025$ and 0.05 at $\psi=90^{\circ}$ and $\psi=45^{\circ}$ are studied numerically at $\mathrm{X}_{i}=2.747$ from its leading and the following conclusions are drawn from the study:

(1) With the use of vortex generator, in the triangular duct the boundary layer on both slant and bottom surface get disturbed and the increased interaction between the cold fluid and hot fluid causes an increase in the Stanton number. Total Increase in Stanton number through the channel with winglet (non-dimensional thickness $\mathrm{c} / 2 \mathrm{H}=$ 0.05 at $\psi=45^{\circ}$ ) is $19.7 \%$ with respect to channel without winglet.

(2) Additional thickness of vortex generator provides more contact area to transfer the heat at the expanse of more pumping power due to the increased channel wall shear stress and form drag. The pressure drop increases by $1.02 \%$ with adding $\mathrm{c} / 2 \mathrm{H}$ amount of non-dimensional thickness and the total pressure penalty is $7.8 \%$ with respect to channel without winglet.

(3) The heat transfer enhancement due to triangular winglet can be utilized in terms of reduction of size of the heat exchanger. $50 \%$ reduction in size is accomplished by using the triangular winglet with adding thickness $(\mathrm{c} / 2 \mathrm{H})$ and tilting it at $\psi$ of $45^{\circ}$.

\section{NOMENCLATURE}

$\mathrm{B}_{\mathrm{t}} \quad$ Bulk Temperature, ${ }^{\circ} \mathrm{C}$

$\mathrm{D}_{\mathrm{H}} \quad$ Hydraulic diameter, $\mathrm{m}$

f Friction factor,

h Heat transfer coefficient, $\mathrm{W} /\left(\mathrm{m}^{2} \cdot \mathrm{K}\right)$

$\mathrm{H} \quad$ Characteristic length dimension (vertical distance between the plates)

$j \quad$ Colburn factor

$\mathrm{k} \quad$ Thermal conductivity of the fluid, $\mathrm{W} /(\mathrm{m} \cdot \mathrm{K})$

L Non-dimensional Length of heat exchanger

$\mathrm{Nu} \quad$ Local Nusselt number based on bulk temperature of the fluid

$\mathrm{Nu}_{\mathrm{sa}} \quad$ Combine average Nusselt number based on bulk temperature of the fluid

$\mathrm{P} \quad$ Non-dimensional pressure

Pr Prandtl number

q Heat flux, $\mathrm{W} / \mathrm{m}^{2}$

Re Reynolds number

St Stanton number

t Time, $\mathrm{s}$

$\mathrm{T}$ Temperature, $\mathrm{K}$

$\mathrm{U}_{\mathrm{av}} \quad$ Average velocity of the fluid at the channel inlet in axial direction, $\mathrm{m} / \mathrm{s}$

$\mathrm{U}_{\mathrm{c}} \quad$ Mean channel outflow velocity, $\mathrm{m} / \mathrm{s}$

$\mathrm{u}, \mathrm{v}, \mathrm{w}$ Axial, normal and spanwise component of velocity, $\mathrm{m} / \mathrm{s}$

$\mathrm{U}, \mathrm{V}, \mathrm{W}$ Axial, normal and spanwise component of velocity (non-dimensional)

$\mathrm{x}, \mathrm{y}, \mathrm{z} \quad$ Axial, normal and spanwise coordinates, $\mathrm{m}$

$\mathrm{X}, \mathrm{Y}, \mathrm{Z}$ Axial, normal and spanwise coordinates (non- dimensionalised by $\mathrm{H}$ )

$\alpha \quad$ Thermal diffusivity, $\mathrm{m}^{2} / \mathrm{s}$

$\beta \quad$ Angle of attack of the wing, degree

$\psi$ Acute angle of the winglet, degree

$\theta \quad$ Temperature (non-dimensional)

$\tau \quad$ Time (non-dimensional)

$v \quad$ Kinematic viscosity of the fluid, $\mathrm{m}^{2} / \mathrm{s}$

\section{Subscript}

av average

m Mean

o Properties in channel without winglet

sa Spanwise condition of channel walls

w Wall 


\section{ACKNOWLEDGEMENT}

The Author likes to express his gratitude to Dr. R. Vasudevan (Formerly Professor NIT, Kurukshetra) \& Dr. G. Biswas (Director, IIT Gawahati) for motivating and helping him to work in the field of CFD.

\section{REFERENCES}

[1] M. Fiebig, "Embedded vortices in internal flow: heat transfer and pressure loss enhancement", International Journal of Heat and Fluid Flow, Vol. 16, pp.376-388, (1995).

[2] A.M. Jacobi, and R.K. Shah, "Heat transfer surface enhancement through the use of longitudinal vortices: a review of recent progress", Experimental Thermal and Fluid Science, Vol. 11, pp.295-309, (1995).

[3] K. Torii, and J. Yanagihara, "The Effects of Longitudinal Vortices on Heat Transfer of Laminar Boundary", International Journal Series-II JSME, Vol. 32, pp.359-402, (1989).

[4] A.Y. Turk, and G.H. Junkhan, "Heat Transfer Enhancement Downstream of Vortex Generators on a Flat Plate", Proceedings of the Eighth International Heat Transfer Conference, 6, pp. 2903-2908, (1986).

[5] M. Fiebig, P. Kallweit, and N. K. Mitra, "Wing Type Vortex Generators for Heat Transfer Enhancement", Proc. Eighth Int. Heat Transfer Conf., Hemisphere, New York., Vol. 6, pp.2909-2913, (1986).

[6] M. Fiebig, P. Kallweit, N.K. Mitra, and S. Tiggelbeck, "Heat Transfer Enhancement and Drag by Longitudinal Vortex Generators in Channel Flow", Experimental Thermal Fluid Science, Vol. 4, pp.103114, (1991).

[7] G. Biswas, N.K. Mitra, and M. Fiebig, "Computation of Laminar Mixed Convection Flow in a Channel with Wing Type Built-in Obstacles", Journal of Thermophysics, Vol.3, pp. 447-453, (1989).

[8] G. Biswas, and H. Chattopadhyay,"Heat Transfer in a Channel with Built-in Wing-Type Vortex Generators”, Int. Journal of Heat Mass Transfer, Vol.35, pp.803- 814, (1992).

[9] G. Biswas, K. Torii, D. Fujii, and K. Nishino, "Numerical and experimental determination of flow structure and heat transfer effects of longitudinal vortices in a channel flow", Int. Journal of Heat Mass Transfer, 39:pp.3441-3451, (1996).

[10] R. Vasudevan, V. Eswaran, and G. Biswas, "Winglet-Type Vortex Generators For Plate Fin Heat Exchangers Using Triangular Fins”, Numerical Heat Transfer, Part A, Vol. 58, pp.533-555, (2000).

[11] T. M. Liou, C.C. Chen, and T.W. Tsai, "Heat Transfer and Fluid Flow in a Square Duct with 12 Different Shaped Vortex Generators," Journal of Heat Transfer, Vol. 122, pp. 327-335, (2000).

[12] A. Sohankar and L. Davidson, "Effect of Inclined Vortex Generators on Heat Transfer Enhancement in a Three-Dimensional Channel”, Numerical Heat Transfer, Part A, Vol.39, pp. 443-448, (2001).

[13] A. Sohankar, "Heat transfer augmentation in a rectangular channel with a vee-shaped vortex generator. International Journal of Heat and Fluid Flow, 28:pp. 306-317, (2007).

[14] S.R. Hiravennavar, E.G. Tulapurkara, and G. Biswas, "A note on the flow and heat transfer enhancement in a channel with built-in winglet pair”, International Journal of Heat and Fluid Flow, Vol.28, pp.299-305, (2007).

[15] J. M. Wu, and W. Q. Tao, "Numerical study on laminar convection heat transfer in a rectangular channel with longitudinal vortex generator Part A: Verification of field synergy principle”, International Journal of Heat and Mass Transfer, Vol. 51, pp.1179-1191, (2008).

[16] J. M. Wu, and W. Q. Tao, "Numerical study on laminar convection heat transfer in a rectangular channel with longitudinal vortex generator. Part B: Parametric study of major influence factors" International Journal of Heat and Mass Transfer, Vol. 51, pp.3683-3692, (2008)

[17] L. T. Tian, Y. L. He, Y. G. Lei, and W. Q. Tao, "Numerical study of fluid flow and heat transfer in a flat plate channel with longitudinal vortex generators by applying field synergy principle analysis", International Communications in Heat and Mass Transfer, Vol. 36, pp.111-120, (2009).

[18] G. Sachdeva, K.S. Kasana, and R. Vasudevan, "Numerical Analysis of a Plate-Fin Cross Flow Heat Exchanger Having Plane Triangular Secondary Fins and Inline Arrangement of Rectangular Wing Vortex Generator”, International Journal of Applied Engineering Research, Vol-4, pp.1705-1713, (2009).

[19] G. Sachdeva, K.S. Kasana, and R. Vasudevan, "Computation of Heat Transfer Enhancement in a Plate- Fin Heat exchanger with Triangular Inserts and Delta Wing Vortex Generator", International Journal for 
Numerical Methods in Fluids, Vol-63, pp. 1031-1047, (2010).

[20] M. Gupta, K.S. Kasana, and R. Vasudevan, "Numerical Study of Effect on Flow Structure and Heat Transfer with a Rectangular Winglet Pair in a Plate-Fin Heat Exchanger, Journal of Mechanical Engineering Science, 223, pp. 2109-2115, (2009).

[21] JiinYuh Jang, Ling-Fang Hsu, and Jin-Sheng Leu, "Optimization of the span angle and location of vortex generators in a plate-fin and tube heat exchanger, International Journal of Heat and Mass Transfer, 67, pp. 432-444, (2013).

[22] Leandro O. Salviano, Daniel J. Dezan, Jurandir I. and Yanagihara, "Optimization of winglet-type vortex generator positions and angles in plate-fin compact heat exchanger: Response Surface Methodology and Direct Optimization", International Journal of Heat and Mass Transfer, 82, pp. 373-387(2015).

[23] Li Li , Xiaoze Du, Yuwen Zhang, Lijun Yang, and Yongping Yang, "Numerical simulation on flow and heat transfer of fin-and-tube heat exchanger with longitudinal vortex generators", International Journal of Thermal Sciences, 92, pp. 85-96, (2015).

[24] F. H. Harlow, and J. E. Welch, "Numerical Calculation of Time Dependent Viscous Incompressible Flow of Fluid with Free surface”, Physics Fluids, Vol.8, pp.2182- 2188, (1965).

[25] C. W. Hirt, and J. L. Cook, "Calculating Three Dimensional Flows around Structures and over Rough Terrain”, Journal of Computational Physics, Vol. 10, pp.324-340, (1972).

[26] I. Orlanski, "A Simple Boundary Condition for unbounded Flows", Journal of Computational Physics, Vol.21, pp.251-269, (1976). 